\title{
Turmeric (Curcuma longa L.) extract may prevent the deterioration of spatial memory and the deficit of estimated total number of hippocampal pyramidal cells of trimethyltin-exposed rats
}

\section{Sapto Yuliani, Mustofa \& Ginus Partadiredja}

To cite this article: Sapto Yuliani, Mustofa \& Ginus Partadiredja (2017): Turmeric (Curcuma longa L.) extract may prevent the deterioration of spatial memory and the deficit of estimated total number of hippocampal pyramidal cells of trimethyltin-exposed rats, Drug and Chemical Toxicology, DOI: 10.1080/01480545.2017.1293087

To link to this article: http://dx.doi.org/10.1080/01480545.2017.1293087

Published online: 25 Apr 2017.

Submit your article to this journal

View related articles $₫$

View Crossmark data $\asymp$ 


\title{
Turmeric (Curcuma longa L.) extract may prevent the deterioration of spatial memory and the deficit of estimated total number of hippocampal pyramidal cells of trimethyltin-exposed rats
}

\author{
Sapto Yuliani ${ }^{\mathrm{a}}$ (D) Mustofa $^{\mathrm{b}}$ (D) and Ginus Partadiredja ${ }^{\mathrm{c}}$ (D) \\ ${ }^{a}$ Faculty of Pharmacy, Ahmad Dahlan University, Yogyakarta, Indonesia; ${ }^{b}$ Department of Pharmacology and Therapy, Faculty of Medicine, \\ Universitas Gadjah Mada, Yogyakarta, Indonesia; 'Department of Physiology, Faculty of Medicine, Universitas Gadjah Mada, Yogyakarta, \\ Indonesia
}

\begin{abstract}
Context: Protection of neurons from degeneration is an important preventive strategy for dementia. Much of the dementia pathology implicates oxidative stress pathways. Turmeric (Curcuma longa L.) contains curcuminoids which has anti-oxidative and neuro-protective effects. These effects are considered to be similar to those of citicoline which has been regularly used as one of standard medications for dementia.
\end{abstract}

Objective: This study aimed at investigating the effects of turmeric rhizome extract on the hippocampus of trimethyltin (TMT)-treated Sprague-Dawley rats.

Materials and methods: The rats were divided randomly into six groups, i.e., a normal control group (N); Sn group, which was given TMT chloride; Sn-Cit group, which was treated with citicoline and TMT chloride; and three Sn-TE groups, which were treated with three different dosages of turmeric rhizome extract and TMT chloride. Morris water maze test was carried out to examine the spatial memory. The estimated total number of CA1 and CA2-CA3 pyramidal cells was calculated using a stereological method.

Results: The administration of turmeric extract at a dose of $200 \mathrm{mg} / \mathrm{kg}$ bw has been shown to prevent the deficits in the spatial memory performance and partially inhibit the reduction of the number of CA2-CA3 regions pyramidal neurons.

Discussion: TMT-induced neurotoxic damage seemed to be mediated by the generation of reactive oxygen species and reactive nitrogen species. Turmeric extract might act as anti inflammatory as well as anti-oxidant agent.

Conclusions: The effects of turmeric extract at a dose of $200 \mathrm{mg} / \mathrm{kg}$ bw seem to be comparable to those of citicoline.
ARTICLE HISTORY

Received 22 October 2015

Revised 24 May 2016

Accepted 5 February 2017

\section{KEYWORDS}

Curcuma longa L.; trimethyltin; Morris water maze; pyramidal cell; stereology

\section{Introduction}

Dementia refers to a collective symptom encompassing disturbances on memory, thinking, and social abilities, which are sufficiently severe to hinder normal daily life (Chertkow et al. 2008). This disorder seems to primarily implicate oxidative stress-induced neuronal damage in hippocampus, limbic system, and cerebral cortex, which are important sites for learning and memory processing (Mcllroy and Craig 2004). These brain regions seem to be susceptible to oxidative stress (Butterfield 2011), because of their high content of unsaturated fatty acids. Unfortunately, their anti-oxidative defence system is relatively lower than that of other organs (Christen 2000).

One of the more powerful neurotoxicants which is considered to induce oxidative stress is trimethyltin $\left(\mathrm{C}_{3} \mathrm{H}_{9} \mathrm{ClSn}\right.$; TMT; Shuto et al. 2009). Studies on rats revealed that TMT brought about cognitive deterioration and neuronal degeneration, which selectively affected hippocampus, amygdala, and entorhinal cortex of the limbic system, and hence TMTtreated animals may serve as useful models for dementia studies (Geloso et al. 2011). TMT intoxication impaired the spatial learning acquisition of water maze and radial arm maze procedures in rats (Ishida et al. 1997; Park et al. 2011). Severe pyramidal cell loss in the CA1 and CA3 regions as well as in the hippocampal hilus, accompanied by reactive astrogliosis and microglial activation, were observed as a result of TMT intoxication (Brabeck et al. 2002; Geloso et al. 2004).

Protection of neurons from degeneration is an important preventive strategy for dementia. Medications suggested for the prevention of dementia usually include compounds that can impede oxidative damage to neurons (Agrawal et al. 2010) and inhibit the ongoing degenerative processes leading to neuronal deaths (Pan et al. 2008). Numerous phytochemical and pharmacological studies carried out on herbaceous plants have resulted in the development of natural anti-oxidants, including turmeric. Turmeric contains curcuminoids (curcumin, demethoxycurcumin, and bisdemethoxycurcumin) 
(Chattopadhyay et al. 2004) which have been demonstrated to possess anti-oxidative and neuroprotective potentials. The beneficial effects of curcuminoid in the treatment of memory dysfunctions have been reported in animals (Agrawal et al. 2010; Dairam et al. 2007).

To our knowledge there is a lack of studies on the effects of turmeric extract on TMT-treated rats. This study was undertaken to examine the effects of turmeric extract on spatial memory and estimated total number of pyramidal cells in the hippocampus of TMT-exposed rats. These effects were compared to those of citicoline, one of standard medications for dementia.

\section{Materials and methods}

\section{Materials}

Turmeric rhizome powder was purchased from CV. Merapi Farma, Yogyakarta, Indonesia. The botanical origin of the turmeric was identified and authenticated by Mr. Heri Setiyawan, a field botanist from the Faculty of Biology, University of Ahmad Dahlan, Yogyakarta, Indonesia. Trimethyltin chloride and curcumin were purchased from Sigma-Aldrich, Inc., St. Louis, MO. Citicoline was purchased from Bernofarm Pharmaceutical Company, Indonesia. The analytical grade methanol and chloroform were purchased from Merck, Germany.

\section{Animals}

Sixty adult male Sprague-Dawley rats (195-215 g) were obtained from the animal house of Universitas Gadjah Mada. The rats were allowed to acclimatize themselves for at least 6 days prior to the experimentation. The animals were kept in individual cages under standard housing conditions with the room temperature of $24-26^{\circ} \mathrm{C}$, humidity of $60-65 \%$, and a $12 / 12 \mathrm{~h}$ natural light/dark cycle. Food and water were available ad libitum. The experimental procedures were approved by the Ethics Committee of the Integrated Research and Testing Laboratory, Universitas Gadjah Mada (approval number 130/KEC-LPPT/XII/2013).

\section{Extraction of turmeric rhizome}

The extract of turmeric rhizome was prepared by the maceration of $500 \mathrm{~g}$ of turmeric rhizome powder in $1.25 \mathrm{~L}$ of $96 \%$ ethanol. The solvent was removed under reduced pressure using a rotary evaporator (Heidolph, Germany) and this procedure gave a yield of $30.38 \%(\mathrm{w} / \mathrm{w})$ of the ethanol extract. The curcumin compound was identified by thin layer chromatography (TLC) using silica gel $60 \mathrm{~F} 254$ as the stationary phase, chloroform:methanol (9:1 ratio) as the mobile phase, and curcumin as the standard. The concentration of curcumin which represented the major active content of the extract was then measured using TLC scanner densitometer (CAMAG, Switzerland) operated at a wavelength of $426 \mathrm{~nm}$ and found to be $28.08 \%$. The turmeric rhizome extract was finally dissolved in the sodium-carboxy methyl cellulose (CMC-Na) solution prior to oral administration to the rats.

\section{Experimental design}

The rats were divided randomly into six groups consisting of 10 rats for each group, namely $\mathrm{N}$ group (normal group), which received oral CMC-Na solution and intra-peritoneal injection of $0.9 \%$ saline; Sn group (control group), which was given oral CMC-Na solution and intra-peritoneal injection of TMT chloride dissolved in 0.9\% saline (Park et al. 2011); Sn-Cit group, which was treated with oral $200 \mathrm{mg} / \mathrm{kg}$ body weight (bw) of citicoline/Cit solution and TMT chloride injection; and Sn-TE100, Sn-TE200, and Sn-TE300 groups, which were treated with oral 100,200 , and $300 \mathrm{mg} / \mathrm{kg} \mathrm{bw}$, respectively, of turmeric rhizome extract (TE), besides intra-peritoneal injection of TMT chloride. The turmeric rhizome extract and citicoline solutions were given at day 1 up to day 28 of experiment, whereas the TMT chloride injection given as a single dose of $8 \mathrm{mg} / \mathrm{kg}$ bw was administered at day 8 of experiment.

\section{Morris water maze test}

Morris water maze (MWM) test were carried out one day after the day of the last treatment of the rats (i.e., day 29) and the test lasted for 7 days. The tests referred to a slightly modified method of Uygur and Arslan (Uygur and Arslan 2010). For this purpose, a white circular tank with a diameter of $150 \mathrm{~cm}$ and a height of $40 \mathrm{~cm}$ was used. The tank was filled with $25 \pm 2^{\circ} \mathrm{C}$ water to the depth of $18-19 \mathrm{~cm}$ (Hermawati et al. 2014). This depth was considered sufficient to prevent the hind legs and the tails of the rats from touching the bottom of the pool. The pool was divided equally into four imaginary quadrants (i.e., quadrants $A, B, C$, and D). A circular platform made of a white tin container (diameter $13 \mathrm{~cm}$ and height $16.5 \mathrm{~cm}$ ) was placed in the middle of one randomly selected quadrant with its top surface being $1.5-2.5 \mathrm{~cm}$ below the surface of the water. Coconut milk was added to the tank in order to make the water opaque and therefore hid the platform from the sights of the rats. The position of the platform was kept constant for each rat throughout the experiment. Two different starting points were equally spaced around the perimeter of the pool of each quadrant, thus there were eight starting points. There were numerous fixed-visual cues outside the tank in the testing room, such as a poster, a table, a door, and the experimenter. A video camera (Prolink, Taiwan) was mounted above the approximate centre of the pool and connected to a personal computer; enabling the observation on the behaviour of the rats.

The water maze procedure consisted of three phases that were the escape acquisition, probe trial, and sensorimotor test phases. Each rat received four trials per day for five consecutive days during the escape acquisition phase. For each trial, a given rat was placed in the water with its head facing towards the inner wall of the pool at one of the randomly assigned starting points. Four starting points were selected randomly amongst the eight starting points. Each starting point was used once in a given day for each rat. The rat was allowed to swim for a maximum of $60 \mathrm{~s}$ to find the platform. Once the rat located the platform, it was allowed to remain on top of the platform for $15 \mathrm{~s}$. If an animal could not find 
the platform within this period of time, it was guided to the platform by the experimenter and allowed to stay on the platform for $15 \mathrm{~s}$. The latency (s) to find the platform was recorded. The length of the swimming track (path length) of the rat was measured using a curvimeter (Silva Sweden $A B$, Bromma, Sweden).

One day after the acquisition period, a single probe trial was performed. The platform was removed from the water and the rats were given one trial for $60 \mathrm{~s}$. The time spent and the number of crossover in the quadrant where the platform had been previously located (target quadrant) was recorded. On the last day (day 7), the cued test/sensorimotor test was conducted to assess the possible sensory, motor, or motivational deficits of the rats. The surface of the escape platform was made visible (above the surface of the water) and a coloured flag pole was attached to it. Each rat had to perform four trials. The rat was required to locate the visible platform within $60 \mathrm{~s}$. The latency to find the platform was recorded.

\section{Stereological analyses}

\section{Tissue preparation and blocks sectioning}

One day following the sensorimotor test, the rats were euthanized by inhalation of $\mathrm{CO}_{2}$. The cerebrums of the rats were then carefully dissected out from the skull. The right cerebral hemispheres were immersed in $10 \%$ formaldehyde in phosphate buffer saline for the next 6 days. Afterwards, the hippocampi of these right cerebral hemispheres were carefully removed from the brains, underwent histological processing, and eventually were embedded in paraffin blocks. The paraffin blocks were sectioned using a Reichert Wein microtome (Nr13137, Austria) at a thickness $(t)$ of $3 \mu \mathrm{m}$. The first sections containing hippocampal tissues were regarded as the first sections, and the next sections were numbered sequentially. One pair of sections per 200 sections was sampled randomly (by lottery) and systematically throughout all sections for further stereological analyses. This procedure was repeated until the given hippocampus was exhaustively sectioned (Partadiredja and Bedi 2010). The number of pairs of sections obtained was between three and seven pairs. The sampled sections were mounted on slides and stained with toluidine blue.

Estimation of the volumes of hippocampal regions and total number of CA1 and CA2-CA3 regions pyramidal cells The volumes of the CA1 and CA2-CA3 regions were estimated using the Cavalieri principle (Gundersen and Jensen 1987; Miki et al. 2005; Partadiredja and Bedi 2010). One section of each pair of sections was viewed under a light microscope (XSZ, PR China) fitted with a $\times 4$ objective. The images of hippocampi were photographed using a digital camera (Optilab Advance, Miconos, Indonesia) which was attached to the microscope and connected to a laptop computer. The pictures of hippocampus of a given animal were then combined into a montage demonstrating the entire hippocampal formation using Adobe Photoshop CS6 software (Adobe System Inc., San Jose, CA). The exact final magnification of each montage was determined using a micrometer scale

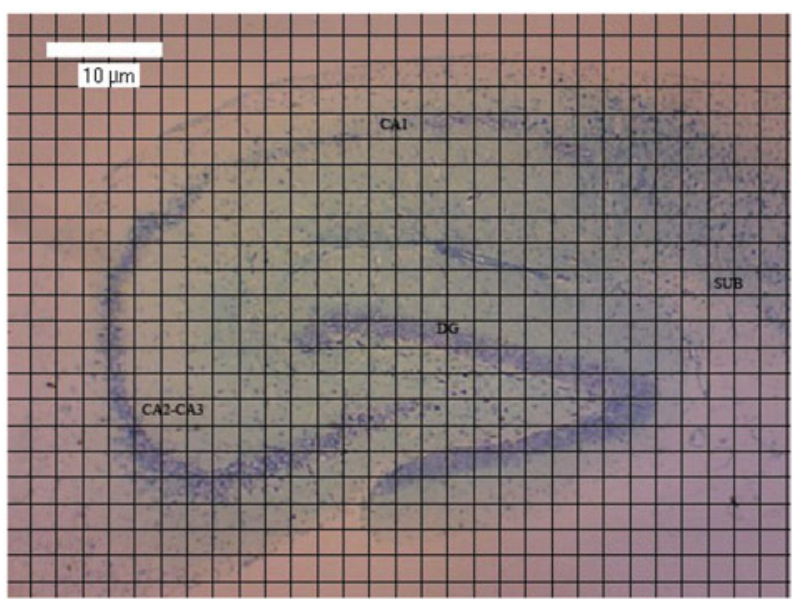

Figure 1. A light micrograph of toluidine blue-stained horizontal section of the hippocampus with a lattice having a regular array of test points $10 \mathrm{~mm}$ apart. Ammon's horn consists of CA1, CA2, and CA3 pyramidal cell layer regions (DG: dentate gyrus; SUB: subiculum).

(Ted Pella, Inc., Redding, CA, Prod. No. 2280-10) and found to be $\times$ 107.9. A virtual grid composed of test points spaced $10 \mathrm{~mm}$ apart was superimposed on the entire hippocampus image (see Figure 1). Each point of the test grid represented an area $(a / p)$ of $0.00859 \mathrm{~mm}^{2}$. The number of points falling on the CA1 or CA2-CA3 regions of each section sampled for any given animal was counted. The total number of points $(\Sigma P)$ for each rat was calculated from the sum of all points falling on all sections in a given rat. The number of points counted per animal was around 38-354 points. The reference volume of the CA1 or CA2-CA3 regions was calculated using the formula (Howard and Reed, 2005):

$$
V_{\text {ref }}=T *(\mathrm{a} / \mathrm{p}) * \Sigma P
$$

where $(a / p)$ or area per point is the area represented by each point and $T$ is the distance between any given section and subsequent section $(200 \times t=200 \times 3 \mu \mathrm{m}=600 \mu \mathrm{m})$.

The numerical densities of the pyramidal neurons of the CA1 and CA2-CA3 regions were determined using physical disector probes. A physical disector consisted of a pair of consecutive sections. For a disector pair, one section was referred to as the 'sample section' and the other as the 'lookup section'. The distance between sections $(h)$ was equal to the section thickness $(t)$ (Partadiredja and Bedi 2010; Sterio, 1984; West 2012a).

Each section in a given pair was observed under a $\times 10$ objective on the microscope equipped with the digital camera and connected to the computer. The fields of view of hippocampal regions were scanned in a raster fashion. In order to select the fields of view for further analyses, a systematic random sampling procedure was applied by selecting a number between 1 and 10, and this number was used for determining the first fields of view. Subsequently, every 10th fields of view were sampled until the whole hippocampal regions were exhaustively scanned. This sampling strategy yielded approximately 2-6 fields of view per region. The images of the selected fields were captured and stored in the computer. The corresponding fields were then identified in the given pair of the sections and their images were also photographed and stored in the computer. The final magnification of the 

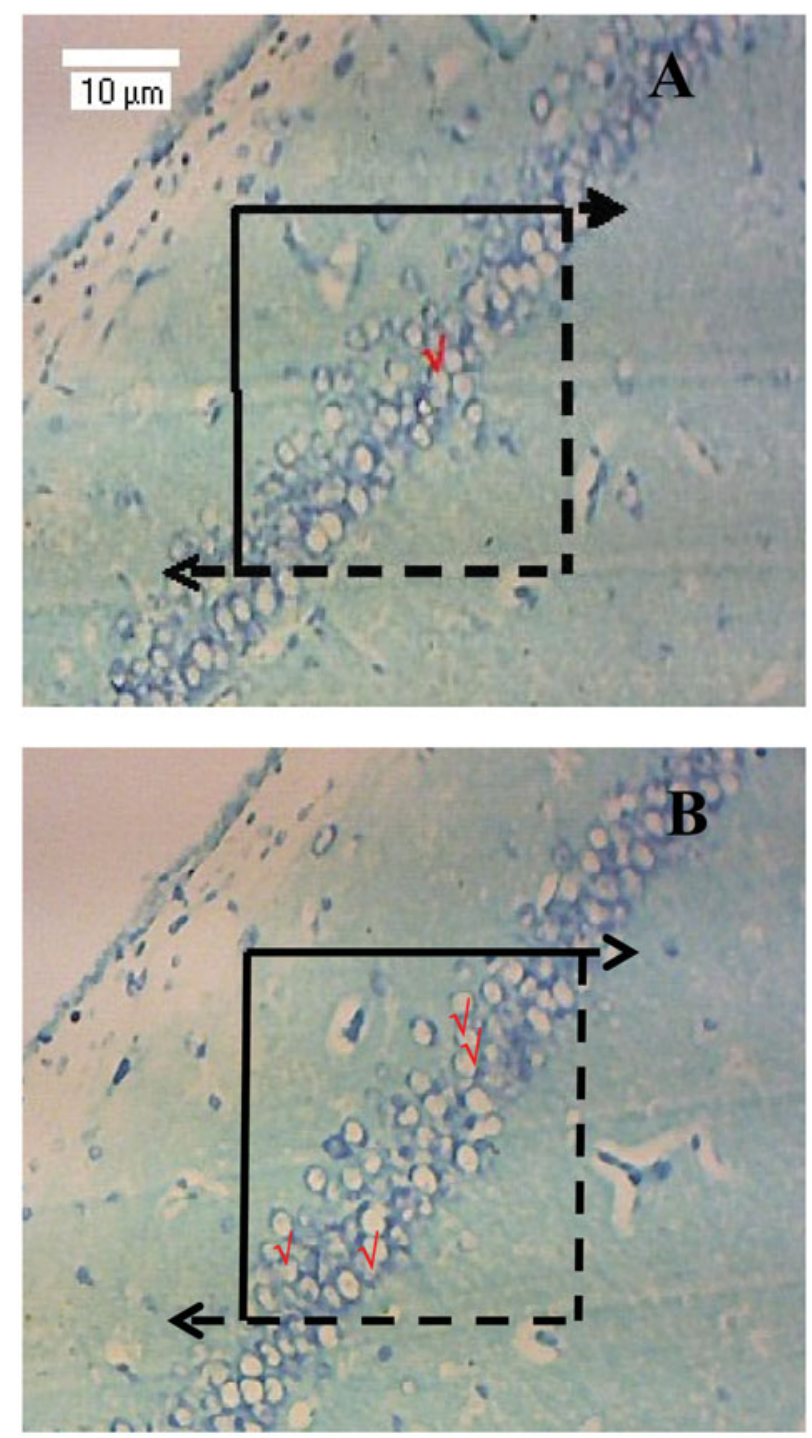

Figure 2. (A) and (B) Micrographs from the CA1 pyramidal cell layer of two consecutive sections of $3 \mu \mathrm{m}$ thickness representing the 'sample section' and 'lookup section' to show the principle of cells counting using physical disector probes. The rectangular frame represents the counting area; broken lines represent the forbidden lines; solid lines represent the inclusion lines. Neurons showing nuclear profiles were used as counting units. The pyramidal cell nuclei, which appear in one section but not in the adjacent section, are marked with red checkmark ( $)$.

printed images was calculated using the stage micrometer and found to be $\times 280$. The images were stored in a digital format and printed using Canon MP 237 printer (Canon Inc., Kyoto, Japan) on normal paper. Each printed image from the 'sample' and 'look-up' sections was superimposed with a rectangular frame (see the example at Figure 2). The area of the rectangular counting frame was calculated to be $0.01148 \mathrm{~mm}^{2}$.

A disector count $(\mathrm{Q}-)$ was made when a neuronal nuclear profile was present in the 'sample section' but not in the 'look-up section' (West 2012a) using the 'forbidden line rule' (Gundersen and Jensen 1987). In order to achieve efficiency in sampling, the micrographs were used in turn; the 'sample sections' were then used as 'look up sections' and vice versa. The number of $\mathrm{Q}-$ per animal was between 32 and 414 profiles. The numerical densities (Nv) of pyramidal cells were estimated using the formula (Partadiredja and Bedi 2010; West 2012a):

$$
\mathrm{Nv}=\frac{\Sigma Q-}{a h}
$$

where $a$ is the total area of test section sampled for that given region. The total number of pyramidal neurons in any given hippocampus was eventually estimated by multiplying the reference volume of the hippocampal regions by the related numerical density of neurons $\left(V_{\text {ref }} \times \mathrm{Nv}\right)$. This stereological procedure was carried out blindly with the experimenter not knowing to which groups the specimens belonged.

\section{Statistical analyses}

The data on the latency and path length of the escape acquisition phase of MWM test were not normally distributed and not homogenous, and therefore were transformed into log 10 data. These data were analysed using a repeated measure analyses of variance (ANOVA) method. The data of the probe and sensorimotor tests of MWM, as well as the estimated volume, numerical density, and total number of pyramidal cells of the hippocampus were analysed using a one-way ANOVA procedure followed by the post-hoc Tukey HSD test.

The estimates of precision in the stereological analyses of the volumes of hippocampal regions and total number of pyramidal cells of each regions were calculated using the formula $\mathrm{CV}_{\text {tot }}^{2}=\mathrm{CV}_{\text {bio }}^{2}+\mathrm{CE}_{\text {tot }}^{2}$ (West 2012b), where $\mathrm{CV}_{\text {tot }}$ (total coefficient of variance) represents the total variability within and between groups, $\mathrm{CE}_{\text {tot }}$ (total coefficient of error) represents stereological noises, and $\mathrm{CV}_{\text {bio }}$ (biological coefficient of variations) represents the biological variations between individuals. The sampling strategy is considered optimal when $\mathrm{CE}_{\text {tot }} \leq \frac{1}{2} \mathrm{CV}_{\text {tot }}$ (Boyce et al. 2010) or when $\mathrm{CE}_{\text {tot }}^{2} / \mathrm{CV}_{\text {tot }}^{2}$ is between 0.2 and 0.5 (Nyengaard, personal communication). All statistical analyses were done using SPSS Software Version 21 for Windows. The significance level was set at $p<0.05$.

\section{Results}

\section{Spatial memory}

Figures $3(A)$ and $(B)$ show the data of the mean latencies and path lengths of all groups of rats to reach the hidden platform in the escape acquisition phase of the MWM procedure. It can be seen from Figure $3(B)$ that the trajectory of the Sn group steadily increased from day 1 to day 5 of the trials. On the other hand, the latency of the Sn group (Figure 3(A)) seemed to follow a generally downward trend from day 1 to day 4, before sharply increasing on day 5 . This was partly because several rats swam quickly at long trajectories before reaching the platform on days 3 and 4, but not on day 5 . Therefore, even though the path lengths of the rats of $\mathrm{Sn}$ group on days 3 and 4 were similar to those on days 1 and 2 , the latencies of the rats on days 3 and 4 were lower than those on days 1 and 2 .

The repeated measure ANOVA of the log 10 of the mean latencies and path lengths of all groups of rats showed that 


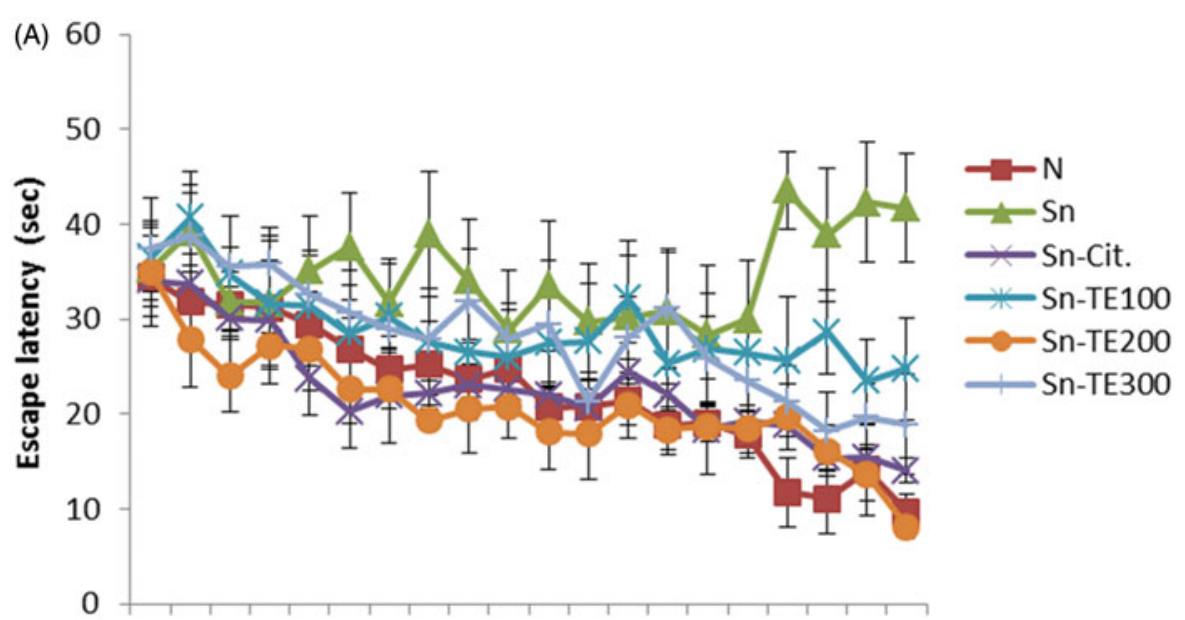

$\begin{array}{lllllllllll}1 & 2 & 3 & 4 & 5 & 6 & 7 & 8 & 9 & 1011121314151617181920\end{array}$

Day 1 Day $2 \frac{}{\text { Day } 3} \frac{}{\text { Day } 4} \frac{}{\text { Day } 5}$

Training Trial

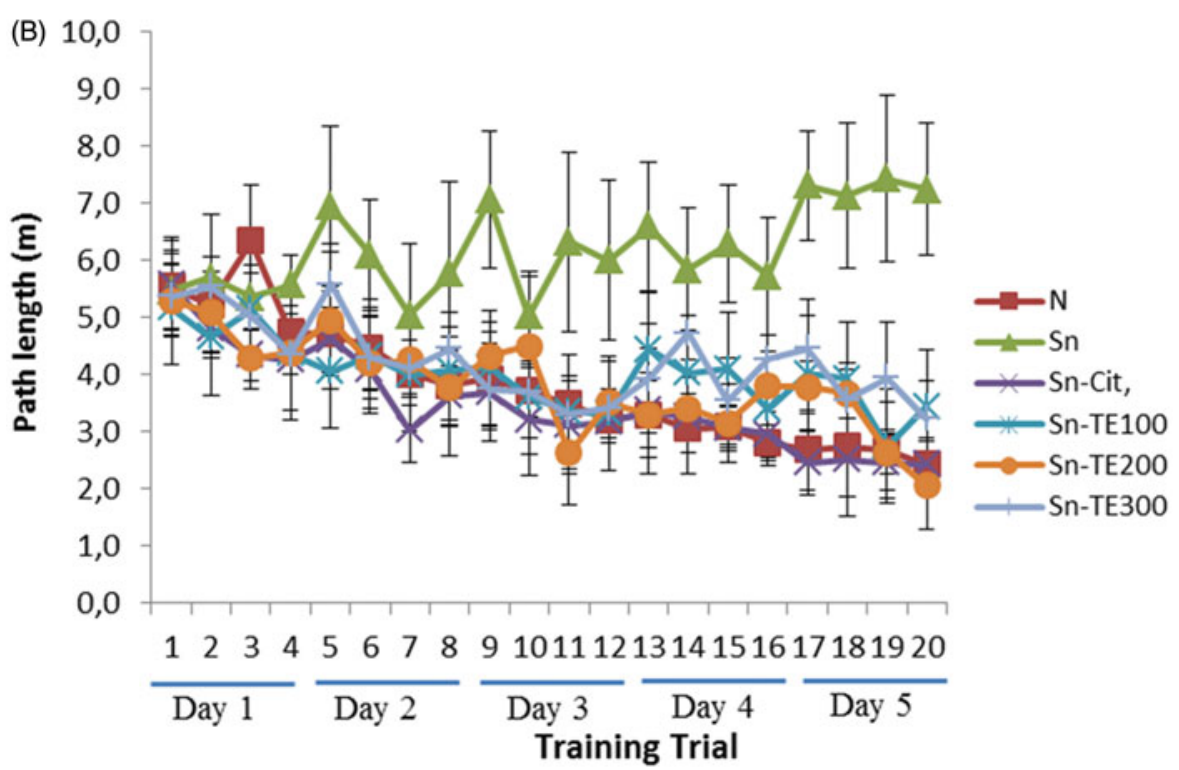

Figure 3. (A) The mean escape latencies (sec) and (B) path lengths $(\mathrm{m})$ to escape to the hidden platform during the acquisition phase of MWM test. The task was performed with four trials per day during the 5-day-acquisition phase.

Table 1. Means \pm SEM of the log 10 transformation of the latency and path length data in the escape acquisition phase of the MWM test.

\begin{tabular}{llll}
\hline Groups & $n$ & \multicolumn{1}{c}{ Latency } & \multicolumn{1}{c}{ Path length } \\
\hline $\mathrm{N}$ & 10 & $1.260 \pm 0.034^{\mathrm{a}}$ & $0.507 \pm 0.070^{\mathrm{a}}$ \\
$\mathrm{Sn}$ & 10 & $1.442 \pm 0.103$ & $0.703 \pm 0.093$ \\
$\mathrm{Sn}$-Cit & 10 & $1.298 \pm 0.063$ & $0.455 \pm 0.074^{\mathrm{a}}$ \\
Sn-TE100 & 10 & $1.384 \pm 0.087$ & $0.504 \pm 0.087^{\mathrm{a}}$ \\
Sn-TE200 & 10 & $1.263 \pm 0.094^{\mathrm{a}}$ & $0.497 \pm 0.080^{\mathrm{a}}$ \\
Sn-TE300 & 10 & $1.393 \pm 0.064$ & $0.539 \pm 0.087$ \\
& & $\mathrm{df}=5,54$ & $\mathrm{df}=5,54$ \\
& & $F=6.703$ & $\mathrm{~F}=4.707$ \\
& & $p=0.000$ & $p=0.001$ \\
\hline
\end{tabular}

${ }^{\mathrm{a}} p<0.05$, compared with Sn group.

there was a significant main effect of groups $(p<0.05)$ but not the interaction between trials and groups (Table 1). Post hoc Tukey HSD test of the escape latencies data showed that the latency of Sn group was significantly higher than that of $\mathrm{N}(p=0.010)$ and Sn-TE200 $(p=0.001)$ groups. There was no difference in latencies between $\mathrm{N}$ group and $\mathrm{Sn}-\mathrm{Cit}$ $(p=0.976)$, Sn-TE100 $(p=0.522)$, and Sn-TE300 $(p=0.620)$ groups, as well as between Sn group and Sn-Cit $(p=0.074)$, Sn-TE100 ( $p=0.467)$, and Sn-TE300 ( $p=0.375)$ groups. The analyses on the data of path lengths revealed that the mean path lengths of Sn group were significantly longer than that of $\mathrm{N}(p=0.010)$, Sn-Cit $(p=0.001)$, Sn-TE100 $(p=0.011)$, and Sn-TE200 ( $p=0.008)$ groups. There were no significant differences in the path lengths between $\mathrm{N}$ group and those of $\mathrm{Sn}$ Cit and all turmeric-treated groups (see Table 1).

In the probe tests, there was a significant main effect of groups $(p<0.05)$ with respect to the percentages of time spent and the number of crossover in the target quadrant where the platform had previously been located (Figures 4 and 5). The percentage of the time spent in the target quadrant of the Sn group was lower than that of $\mathrm{N}(p=0.0001)$, Sn-Cit $(p=0.0001)$, Sn-TE200 $(p=0.0001)$, and Sn-TE300 ( $p=0.010)$ groups. In addition, the percentage of time spent in the target quadrant of Sn-TE100 group was significantly 
lower than that of $\mathrm{N}$ group $(p=0.015)$. The number of crossover in the target quadrant of Sn group was significantly lower than that of Sn-Cit $(p=0.001)$ and Sn-TE200 $(p=0.006)$ groups. There was no significant difference in the number of crossover in the target quadrant between $\mathrm{N}$ group and $\mathrm{Sn}$-Cit $(p=0.099)$ and Sn-TE200 $(p=0.875)$ groups.

One-way ANOVA test of the data of sensorimotor test revealed that there was no significant main effect of groups $(p>0.05)$ in respect of the latency, which therefore indicated that all groups had comparable levels of sensorimotor ability and motivational drive in the visible platform task (Figure 6).

\section{Estimated total number of hippocampal pyramidal cells}

Tables 2 and 3 show the estimated volume, numerical density, and total number of pyramidal cells in CA1 and CA2-CA3 regions. The precision of estimates in stereological analyses $\left(\mathrm{CE}_{\text {tot }}^{2} / \mathrm{CV}_{\text {tot }}^{2}\right)$ of the estimated mean volume and total number of pyramidal cells in the CA1 regions were 0.15 and 0.13 , respectively; whereas those in the CA2-CA3 regions were 0.28 and 0.23 , respectively. These values suggested that the

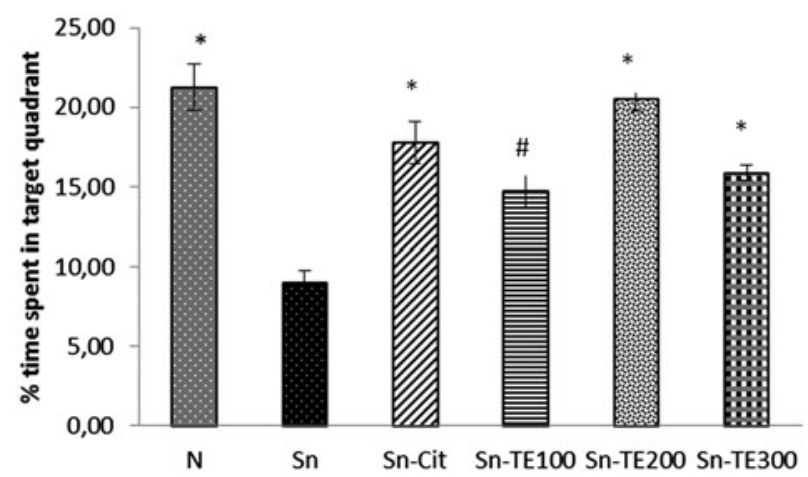

Figure 4. Mean percentages \pm SEM of time spent in the quadrant where the platform had previously been located in the probe trials at day 6 of MWM test. One-way ANOVA: $\mathrm{df}=5,54 ; F=10.735 ; p=0.0001$.

${ }^{*} p<0.05$, compared with Sn group; ${ }^{\#} p<0.05$, compared with $\mathrm{N}$ group. sampling strategy for the data of estimated volume and total number of pyramidal cells was sufficient.

One-way ANOVA of the data of the volume, numerical density, and estimated total number of pyramidal cells in the CA1 and CA2-CA3 regions of hippocampus showed a significant main effect of groups $(p<0.05)$. Post hoc Tukey HSD tests of these data revealed that the volume of pyramidal cells layer of the hippocampal CA1 region of $\mathrm{Sn}$ group was significantly smaller than that of $N(p=0.0001)$ group. However, no significant difference in the volume was found between Sn group and Sn-Cit $(p=0.110)$, Sn-TE100 $(p=0.998)$, Sn-TE200 $(p=0.971)$, and Sn-TE300 $(p=0.998)$ groups. The numerical density of pyramidal neurons of the hippocampal CA1 region of the Sn group was significantly lower than that of $\mathrm{N}$ group $(p=0.012)$. The numerical density of these pyramidal neurons of $\mathrm{N}$ group was higher than that of Sn-Cit $\quad(p=0.002), \quad$ Sn-TE100 $\quad(p=0.011), \quad$ Sn-TE200 $(p=0.001)$, and Sn-TE300 $(p=0.001)$ groups. The estimated total number of pyramidal neurons of the hippocampal CA1 region of the $T$ group was significantly lower than that of the $\mathrm{N}$ group $(p=0.0001)$. There was no significant difference between Sn and Sn-Cit groups, as well as between Sn group and all turmeric-treated groups.

The analyses on the data of volume of pyramidal cells layer of the hippocampal CA2-CA3 region showed that the volume of $\mathrm{Sn}$ group was significantly smaller than that of $\mathrm{N}$ $(p=0.0001)$, Sn-Cit $(p=0.0001)$, and Sn-TE200 $(p=0.004)$ groups. The pyramidal cells layer volume of this region was larger in N group than in Sn-TE100 $(p=0.0001)$ and Sn-TE300 $(p=0.0001)$ groups. On the other hand, there were no significant differences between groups in the numerical density of pyramidal neurons of the hippocampal CA2-CA3 region. The estimated total number of pyramidal cells in the CA2-CA3 region of $\mathrm{Sn}$ group was significantly lower than that of $\mathrm{N}$ group $(p=0.001)$. However, no significant difference in the number of pyramidal neurons in this region was found between Sn group and Sn-Cit $(p=0.095)$ and Sn-TE200 $(p=0.471)$ groups, as well as between $\mathrm{N}$ group and these

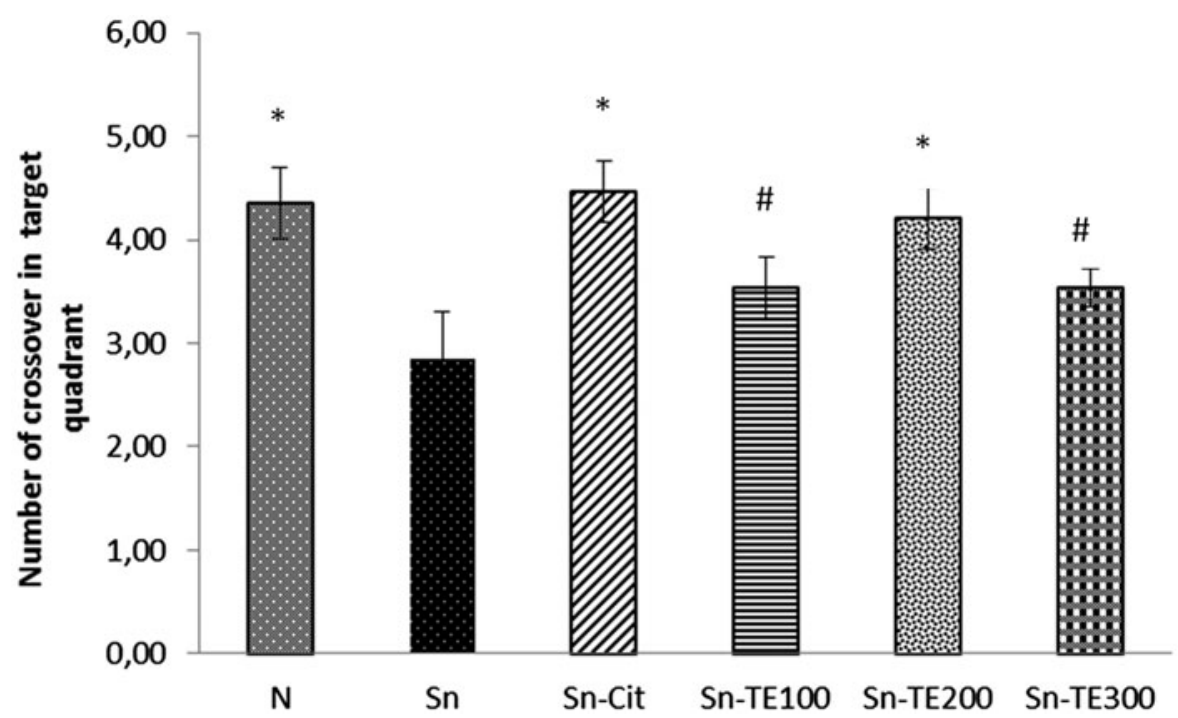

Figure 5. Mean number of crossover \pm SEM in the quadrant where the platform had previously been located in the probe trials at day 6 of MWM test. One-way ANOVA: $\mathrm{df}=5,54 ; F=7.894 ; p=0.0001 .{ }^{*} p<0.05$, compared with $\mathrm{Sn}$ group, $\# p<0.05$, compared with $\mathrm{N}$ group. 


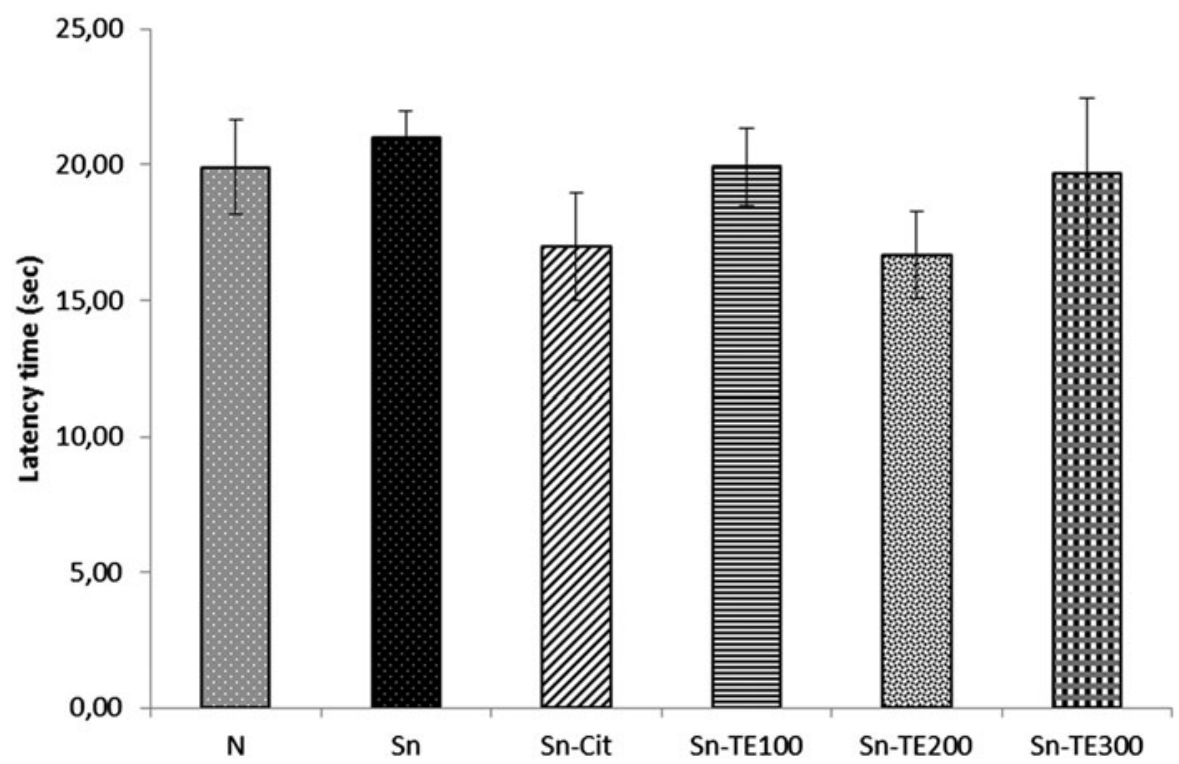

Figure 6. Means \pm SEM of latencies taken to locate the platform in the cued trials (sensorimotor test) of MWM task. One-way ANOVA: df $=5,54 ; F=0.239$; $p=0.944$.

Table 2. Means \pm SD of estimated volume, numerical density, and total number of pyramidal cells in CA1 regions.

\begin{tabular}{|c|c|c|c|c|c|c|c|c|}
\hline Groups & $n$ & $\mathrm{Vol}\left(\mathrm{mm}^{3}\right)$ & CV (Vol) & CE (Vol) & $\mathrm{Nv}\left(/ \mathrm{mm}^{3}\right)$ & Num & CV (Num) & CE (Num) \\
\hline $\mathrm{N}$ & 6 & $0.93 \pm 0.05^{\mathrm{a}}$ & 0.06 & 0.09 & $241727.92 \pm 26848.35^{\mathrm{a}}$ & $225991.11 \pm 30617.77^{a}$ & 0.13 & 0.10 \\
\hline Sn-Cit & 6 & $0.79 \pm 0.33$ & 0.21 & 0.07 & $132925.94 \pm 61900.62^{b}$ & $122234.71 \pm 29865.55^{b}$ & 0.24 & 0.13 \\
\hline Sn-TE100 & 6 & $0.51 \pm 0.21^{b}$ & 0.16 & 0.13 & $143624.25 \pm 82751.55^{b}$ & $87649.32 \pm 38241.09^{b}$ & 0.43 & 0.14 \\
\hline \multirow[t]{3}{*}{ Sn-TE300 } & 6 & $0.59 \pm 0.25^{b}$ & 0.16 & 0.12 & $129422.48 \pm 63082.87^{b}$ & $90601.73 \pm 30735^{\mathrm{b}}$ & 0.34 & 0.15 \\
\hline & & One-way & $\mathrm{CV}_{\text {tot }}=0.25$ & $\mathrm{CE}_{\mathrm{tot}}=0.09$ & One-way & One-way & $\mathrm{CV}_{\text {tot }}=0.36$ & $C E_{\text {tot }}=0.13$ \\
\hline & & ANOVA & $\mathrm{CV}_{\text {bio }}=0.23$ & $\mathrm{CE}_{\mathrm{tot}}^{2} / \mathrm{CV}_{\text {tot }}^{2}=0.15$ & ANOVA & ANOVA & $\mathrm{CV}_{\text {bio }}=0.34$ & $\mathrm{CE}_{\mathrm{tot}}^{2} / \mathrm{CV}_{\mathrm{tot}}^{2}=0.13$ \\
\hline
\end{tabular}

ANOVA: analysis of variance; $\mathrm{CE}_{\text {tot }}$ : total coefficient of error; $\mathrm{CV}_{\text {tot }}$ : total coefficient of variation; $\mathrm{CV}_{\text {bio }}$ : biological coefficient of variation; df: degree of freedom; $n$ : number of subject; Nv: numerical density; Num: mean total number of CA1 pyramidal cells; Vol: mean volumes of CA1 regions ${ }^{a} p<0.05$, compared with Sn group.

${ }^{\mathrm{b}} p<0.05$, compared with $\mathrm{N}$ group.

Table 3. Means $\pm S D$ of estimated volume, numerical density, and total number of pyramidal cells in CA2-CA3 regions.

\begin{tabular}{|c|c|c|c|c|c|c|c|c|}
\hline Group & $n$ & Vol $\left(\mathrm{mm}^{3}\right)$ & CV (Vol) & CE (Vol) & $\mathrm{Nv}\left(/ \mathrm{mm}^{3}\right)$ & Num & CV (Num) & CE (Num) \\
\hline $\mathrm{N}$ & 6 & $1.15 \pm 0.06^{\mathrm{a}}$ & 0.05 & 0.04 & $123881.81 \pm 20163.59$ & $167594.41 \pm 28160.31^{a}$ & 0.17 & 0.1 \\
\hline Sn-Cit & 6 & $0.99 \pm 0.18^{\mathrm{a}}$ & 0.18 & 0.04 & $113894.87 \pm 61136.54$ & $135897.61 \pm 41505.02$ & 0.30 & 0.13 \\
\hline Sn-TE100 & 6 & $0.66 \pm 0.13^{b}$ & 0.19 & 0.09 & $119213.15 \pm 65966.32$ & $92273.89 \pm 32428.09^{b}$ & 0.35 & 0.14 \\
\hline \multirow[t]{4}{*}{ Sn-TE300 } & 6 & $0.65 \pm 0.08^{b}$ & 0.12 & 0.05 & $114798.97 \pm 75595.27$ & $90318.21 \pm 41540.88^{\mathrm{b}}$ & 0.45 & 0.14 \\
\hline & & One-way & $\mathrm{CV}_{\text {tot }}=0.17$ & $C E_{\text {tot }}=0.09$ & One-way & One-way & $\mathrm{CV}_{\text {tot }}=0.30$ & $C E_{\text {tot }}=0.14$ \\
\hline & & ANOVA & $\mathrm{CV}_{\mathrm{bio}}=0.15$ & $\mathrm{CE}_{\mathrm{tot}}^{2} / \mathrm{CV}_{\mathrm{tot}}^{2}=0.28$ & ANOVA & ANOVA & $\mathrm{CV}_{\text {bio }}=0.34$ & $\mathrm{CE}_{\mathrm{tot}}^{2} / \mathrm{CV}_{\text {tot }}^{2}=0.23$ \\
\hline & & & & & & & & \\
\hline
\end{tabular}

ANOVA: analysis of variance; $\mathrm{CE}_{\text {tot: }}$ total coefficient of error; $\mathrm{CV}_{\text {tot }}$ : total coefficient of variation; $\mathrm{CV}_{\text {bio }}$ : biological coefficient of variation; df: degree of freedom; $n$ : number of subject; Nv: numerical density; Num: mean total number of CA2-CA3 pyramidal cells; Vol: mean volumes of CA2-CA3 regions ${ }^{\mathrm{a}} p<0.05$, compared with Sn group;

${ }^{\mathrm{b}} \mathrm{p}<0.05$, compared with $\mathrm{N}$ group.

latter two groups ( $p=0.546$ and $p=0.122$, respectively) (Yuliani 2015).

\section{Discussion}

In this study, we found that rats treated with TMT only (Sn group) suffered from severe deficits in the spatial memory performance during the MWM test. The rats treated with TMT and $200 \mathrm{mg} / \mathrm{kg}$ bw of turmeric extract (Sn-TE200) performed consistently and significantly better than $\mathrm{Sn}$ group in the non-visible platform version of the MWM procedure. Their performances in the latencies, path lengths, percentages of time spent, and the number of crossover in the target quadrants were comparable to those of naive rats ( $\mathrm{N}$ group) and 
rats treated with $200 \mathrm{mg} / \mathrm{kg}$ bw of citicoline (Sn-Cit group). These results likely stemmed from real differences in memory ability of the rats since there were no significant differences between groups in the escape latencies in the visible platform version of the MWM test. The administration of turmeric and citicoline was not able to prevent the deficits of the number of pyramidal cells in the CA1 region of TMT-exposed rats. However, it seems that $200 \mathrm{mg} / \mathrm{kg} \mathrm{bw}$ of turmeric extract and $200 \mathrm{mg} / \mathrm{kg}$ bw of citicoline could partially inhibit the deficits of pyramidal cells in the CA2-CA3 region of TMT-exposed rat.

The precise mechanism of TMT intoxication is not entirely understood (Geloso et al. 2011), although previous studies suggested that TMT-induced neurotoxic damage was mediated by the generation of reactive oxygen species (ROS) and reactive nitrogen species. It was found that the formation of 4hydroxynonenal (4-HNE), which is a major aldehydic product of lipid peroxidation, increased after TMT administration (Shuto et al. 2009). TMT also altered serotonergic and cholinergic systems (Roy et al. 1999), activated protein kinase C in culture and induced apoptotic cascade (Thompson et al. 1996).

TMT-exposed rats developed more extensive lesions in the Cornu Ammonis (CA) region than in the granular cells layer (Geloso et al. 2011) since TMT affected mainly CA1 and CA3 pyramidal neurons (Latini et al. 2010). Our study indicated that the loss of pyramidal neurons in the CA1 region $(59.5 \%$ of the number of pyramidal cells of the normal group) was more than that in the CA2-CA3 region $(49.6 \%$ of the number of pyramidal cells of the normal group). This was apparently due to the differential susceptibility of the cells of these two regions to neurotoxicants or environmental insults (Wang and Michaelis 2010). It was found that CA1 region possessed more NMDA receptors (NMDARs) than CA3 region (Fiacco et al. 2003). The activation of NMDARs by stress oxidative resulted in a much higher increase of $\mathrm{Ca}^{2+}$ level in CA1 neurons than in CA3 neurons (Wang and Michaelis 2010), and eventually might cause more glutamate excitotoxicity as well as apoptosis (Lu et al. 2014; Quincozes-Santos et al. 2014) in the $C A 1$ region than in the $C A 2-C A 3$ region. This argument may also hold true to elucidate the underlying mechanisms of the possible differences in efficacy of turmeric extract on the two regions.

The estimated total number of CA1 and CA2-CA3 pyramidal cells of TMT-treated groups in this study was significantly lower than that of normal group after 28 days of TMT injection. TMT may cause a delayed onset of TMT-induced neuronal death, and the high affinity of rats' haemoglobin for TMT was probably accounted for this late onset (Koczyk 1996). Haemoglobin may serve as a reservoir which slowly and continuously releases TMT into the plasma, from which TMT then enters the brain (Harry et al. 1985). Our study supports previous studies which showed that the most dramatic reduction of cell numbers of TMT-treated rats occurred between 14 and 28 days (Robertson et al. 1987) and that structural damage started to be observed within 2-3 days after TMT administration, became evident within 21 days, and continued to occur during the following few weeks (Whittington et al. 1989). This structural disturbance, which includes the reduction of the number of the $C A$ regions pyramidal cells, might have caused the decrease of the volume of the pyramidal cells layer in this study. It remains to be determined whether this TMT-induced decrease of the volume of pyramidal neurons layer corresponds to the decrease of the volume of the whole hippocampal formation or even the brain of rats. In humans, sometimes dementia is characterized with the reduction of the volume of hippocampus or the brain (Schuff et al. 2009).

It is well known that lesions of the hippocampus in humans and mammals produce severe amnesia for certain memories (Meck et al. 2013). Rats with bilateral hippocampal lesions exhibited impaired spatial memory for the location of a hidden platform (Broadbent et al. 2004). Rats with lesions on the CA1 (Davis et al. 1987) or CA3 (Sutherland et al. 1983) region showed deficits in the MWM task comparable to those with complete hippocampal lesions. The spatial learning impairment associated with TMT in this study is consistent with the previous studies (Park et al. 2011, 2015; Mignini et al. 2012).

Turmeric contains curcumin and its derivates (demethoxycurcumin and bisdemethoxycurcumin) that are proposed to have anti-oxidant potentials. The anti-oxidant activity of curcumin is generally attributed to the curcumin's phenolic and methoxy groups content, which in conjunction with the 1,3diketone-conjugated diene system are capable of scavenging the oxygen radicals (Itokawa et al. 2008). It has been shown that curcumin acts as an anti inflammatory agent in Alzheimer's disease (Giri et al. 2004), as well as neutralizes reactive oxygen and nitric-oxide-based free radicals (Avci et al. 2012). Curcumin administration also decreases mitochondrial dysfunction (Eckert et al. 2013) and protects neurons by increasing Bcl-2 level (Pan et al. 2008).

This study revealed that no linear dose-response relationship occurred in the neuroprotective effects of turmeric extract. Overall, the spatial learning and memory performance as well as stereological results of Sn-TE200 group was the best amongst the three turmeric-extract treated groups. This may be understood in light of possible paradoxical effects of curcumin. Contradictory to the above-mentioned anti-oxidant effects, curcumin has been shown to exert pro-oxidant activities. Such pro-oxidant activities appear to be mediated through the generation of phenoxyl radical of curcumin by peroxidase- $\mathrm{H}_{2} \mathrm{O}_{2}$ system, which co-oxidizes cellular glutathione or Nicotinamide Adenine Dinucleotide Hydride (NADH), to form ROS (Galati et al. 2002). This in turn causes apoptosis (Yoshino et al. 2004). The apoptosis eventually may cause the decrease of the total number of cells. However, the precise dose of curcumin that results in pro-oxidative effects remains unclear so far.

The rats treated with $200 \mathrm{mg} / \mathrm{kg}$ bw of turmeric extract performed similarly to the rats treated with citicoline in the MWM task. In addition, this particular dosage of turmeric extract was found to inhibit the decrease of the number of CA2-CA3 region pyramidal cells at the same degree as citicoline. Nevertheless, both turmeric extract and citicoline were not able to prevent the decrease of the number and apoptosis of CA1 region pyramidal cells. Citicoline (citidine-5-diphosphocholine or (DP-choline) has been regularly used as a neuroprotective and memory enhancing drug 
(Álvarez-Sabín and Román 2011; Rao et al. 2000). It seems that the ability of citicoline to block decomposition and to resynthesize membrane phospholipids (Grieb et al. 2000) enables it to selectively and partially protect CA regions pyramidal neurons, especially in CA2-CA3 regions.

\section{Conclusion}

In summary, $200 \mathrm{mg} / \mathrm{kg}$ bw of turmeric extract administration on rats may prevent the TMT-induced deficits of spatial memory and partially hinder the deficits of pyramidal cells in the CA2-CA3 region. To some extent these effects seem to be comparable to those of citicoline. Further studies are therefore warranted to explore this extract potential to be developed as an alternative medicine for dementia. These may include stereological studies on the effects of turmeric extract on the dentate gyrus, where neurogenesis is still active during adulthood (Bedi 1991; Smart 1990), in TMT-exposed rats. Electrophysiological studies such as investigations on the possible changes of long-term potentiation or long-term depression as a manifestation of memory function might also be important.

\section{Acknowledgements}

This study was a part of Sapto Yuliani's Doctoral thesis. The authors would like to acknowledge the contribution of Sapto Yuliani's late cosupervisor, Dr. Djoko Prakosa, who passed away in December 2014; as well as the technical assistance of Hamam Hudaya, Samidi (Laboratory of Pharmacology, Faculty of Pharmacy, Universitas Ahmad Dahlan), Yulianasari Pulungan, Mutmainnah, Naili Rafi'ah, and Vania Sugestin.

\section{Disclosure statement}

The authors report no declarations of interest.

\section{Funding}

This study was partially funded by the Directorate of Higher Education, Ministry of Education and Culture, Indonesia [grant no.1143.1/K5/KL/ 2013].

\section{ORCID}

Sapto Yuliani (iD http://orcid.org/0000-0002-8454-2370

Mustofa (D) http://orcid.org/0000-0002-0522-8413

Ginus Partadiredja (D) http://orcid.org/0000-0003-0395-4240

\section{References}

Agrawal, R., et al., 2010. Effect of curcumin on brain insulin receptors and memory functions in STZ (ICV) induced dementia model of rat. Pharmacological Research, 61, 247-252.

Álvarez-Sabín, J. and Román, G.C., 2011. Citicoline in vascular cognitive impairment and vascular dementia after stroke. Stroke, 42, S40-S43.

Avci, G., et al., 2012. Curcumin protects against ischemia/reperfusion injury in rat skeletal muscle. Journal of Surgical Research, 172, e39-e46.

Bedi, K.S., 1991. Effects of undernutrition during early life on granule cell numbers in the rat dentate gyrus. Journal of Comparative Neurology, $311,425-433$.
Boyce, R.W., et al., 2010. Design-based stereology introduction to basic concepts and practical approaches for estimation of cell number. Toxicologic Pathology, 38, 1011-1025.

Brabeck, C., et al., 2002. Expression of EMAP-II by activated monocytes/ microglial cells in different regions of the rat hippocampus after trimethyltin-induced brain damage. Experimental Neurology, 177, 341-346.

Broadbent, N.J., Squire, L.R., and Clark, R.E., 2004. Spatial memory, recognition memory, and the hippocampus. Proceedings of the National Academy of Sciences USA, 101, 14515-14520.

Butterfield, D.A., 2011. Oxidative stress in Alzheimer disease: synergy between the Butterfield and Markesbery laboratories. Neuromolecular Medicine, 13, 19-22.

Chattopadhyay, l., et al., 2004. Turmeric and curcumin: biological actions and medicinal applications. Current Science, 87, 44-53.

Chertkow, H., et al., 2008. Diagnosis and treatment of dementia: 3. Mild cognitive impairment and cognitive impairment without dementia. Canadian Medical Association Journal, 178, 1273-1285.

Christen, Y., 2000. Oxidative stress and Alzheimer disease. The American Journal of Clinical Nutrition, 71, 621S-629S.

Dairam, A., et al., 2007. Curcuminoids, curcumin, and demethoxycurcumin reduce lead-induced memory deficits in male Wistar rats. Journal of Agricultural and Food Chemistry, 55, 1039-1044.

Davis, H.P., et al., 1987. Retention of reference memory following ischemic hippocampal damage. Physiology \& Behavior, 39, 783-786.

Eckert, G.P., et al., 2013. Curcumin prevents mitochondrial dysfunction in the brain of the senescence-accelerated mouse-prone 8 . Neurochemistry International, 62, 595-602.

Fiacco, T.A., et al., 2003. Increased density of hippocampal kainate receptors but normal density of NMDA and AMPA receptors in a rat model of prenatal protein malnutrition. Journal of Comparative Neurology, 456, 350-360.

Galati, G., et al., 2002. Prooxidant activity and cellular effects of the phenoxyl radicals of dietary flavonoids and other polyphenolics. Toxicology, 177, 91-104.

Geloso, M.C., et al., 2004. Expression of astrocytic nestin in the rat hippocampus during trimethyltin-induced neurodegeneration. Neuroscience Letter, 357, 103-106.

Geloso, M.C., Corvino, V., and Michetti, F., 2011. Trimethyltin-induced hippocampal degeneration as a tool to investigate neurodegenerative processes. Neurochemistry International, 58, 729-738.

Giri, R.K., Rajagopal, V., and Kalra, V.K., 2004. Curcumin, the active constituent of turmeric, inhibits amyloid peptide-induced cytochemokine gene expression and CCR5-mediated chemotaxis of THP-1 monocytes by modulating early growth response- 1 transcription factor. Journal of Neurochemistry, 91, 1199-1210.

Grieb, P., et al., 2000. CDP-choline, but not cytidine, protects hippocampal CA1 neurones in the gerbil following transient forebrain ischaemia. Folia Neuropathologica, 39, 141-145.

Gundersen, H.J.G. and Jensen, E.B., 1987. The efficiency of systematic sampling in stereology and its prediction. Journal of Microscopy, 147, 229-263.

Harry, G.J., et al., 1985. The use of synapsin I as a biochemical marker for neuronal damage by trimethyltin. Brain Research, 326, 9-18.

Hermawati, E., Sari, D.C.R., and Partadiredja, G., 2014. The effects of black garlic ethanol extract on the spatial memory and estimated total number of pyramidal cells of the hippocampus of monosodium glutamateexposed adolescent male Wistar rats. Anatomical Science International, 90, 275-286.

Howard, C. and Reed, M., 2005. Unbiased stereology. In: Three-dimensional measurement in microscopy, 2nd ed. Oxford: BIOS Scientific Publishers.

Ishida, N., et al., 1997. Trimethyltin syndrome as a hippocampal degeneration model: temporal changes and neurochemical features of seizure susceptibility and learning impairment. Neuroscience, 81, 1183-1191.

Itokawa, H., et al., 2008. Recent advances in the investigation of curcuminoids. Chinese Medicine, 3,. 11.

Koczyk, D., 1996. How does trimethyltin affect the brain: facts and hypotheses. Acta Neurobiologiae Experimentalis (Warsaw), 56, 587-596. 
Latini, L., et al., 2010. Trimethyltin intoxication up-regulates nitric oxide synthase in neurons and purinergic ionotropic receptor 2 in astrocytes in the hippocampus. Journal of Neuroscience Research, 88, 500-509.

Lu, Y., et al., 2014. Transient acidosis induces a preconditioning chloride conductance that protects mouse nodose neurons from NMDAinduced apoptosis (1132.13). The FASEB Journal, 28, 1132-1113.

Mcllroy, S. and Craig, D., 2004. Neurobiology and genetics of behavioural syndromes of Alzheimer's disease. Current Alzheimer Research, 1, 135-142.

Meck, W.H., Church, R.M., and Olton, D.S., 2013. Hippocampus, time, and memory. Behavioral Neuroscience, 127, 655-668.

Mignini, F., et al., 2012. Effects and trimethyltin on hippocampal dopaminergic markers and cognitive behaviour. International Journal of Immunopathology and Pharmacology, 25, 1107-1119.

Miki, T., et al., 2005. Application of the physical disector to the central nervous system: estimation of the total number of neurons in subdivisions of the rat hippocampus. Anatomical Science International, 80, 153-162.

Pan, R., et al., 2008. Curcumin improves learning and memory ability and its neuroprotective mechanism in mice. Chinese Medical Journal (England), 121, 832-839.

Park, H.-J., et al., 2011. Neuroprotective effect of Lucium chinense fruit on trimethyltin-induced learning and memory deficits in the rats. Experimental Neurobiology, 20, 137-143.

Park, S.K., et al., 2015. Ameliorating effects of ethyl acetate fraction from onion (Allium cepa L.) flesh and peel in mice following trimethyltininduced learning and memory impairment. Food Research International, 75, 53-60.

Partadiredja, G. and Bedi, K.S., 2010. Undernutrition during the gestation and suckling periods does not cause any loss of pyramidal neurons in the CA2-CA3 region of the rat hippocampus. Nutritional Neuroscience, $13,102-108$.

Quincozes-Santos, A., et al., 2014. Oxidative stress mediated by NMDA, AMPA/KA channels in acute hippocampal slices: neuroprotective effect of resveratrol. Toxicology in Vitro, 28, 544-551.

Rao, A.M., Hatcher, J.F., and Dempsey, R.J., 2000. Lipid alterations in transient forebrain ischemia: possible new mechanisms of CDP-choline neuroprotection. Journal of Neurochemistry, 75, 2528-2535.

Robertson, D.G., Gray, R.H., and Lalglesia, F.A.D., 1987. Quantitative assessment of trimethyltin induced pathology of the hippocampus. Toxicologic Pathology, 15, 7-17.
Roy, A., et al., 1999. Cholinergic and serotonergic alterations in the rat hippocampus following trimethyltin exposure and fetal neural transplantation. Neuroscience Letters, 259, 173-176.

Schuff, N., et al., 2009. MRI of hippocampal volume loss in early Alzheimer's disease in relation to ApoE genotype and biomarkers. Brain Journal of Neurology, 132, 1067-1077.

Shuto, M., et al., 2009. Endogenous and exogenous glucocorticoids prevent trimethyltin from causing neuronal degeneration of the mouse brain in vivo: involvement of oxidative stress pathways. Journal of Pharmaceutical Sciences, 110, 424-436.

Smart, J.L., 1990. Vulnerability of developing brain to undernutrition. Upsala Journal of Medical Sciences, 48, 21-41.

Sterio, D.C., 1984. The unbiased estimation of number and sizes of arbitrary particles using the disector. Journal of Microscopy, 134, 127-136.

Sutherland, R.J., Whishaw, I.Q., and Kolb, B., 1983. A behavioural analysis of spatial localization following electrolytic, kainate- or colchicineinduced damage to the hippocampal formation in the rat. Behavioural Brain Research, 7, 133-153.

Thompson, T.A., et al., 1996. Induction of apoptosis by organotin compounds in vitro: neuronal protection with antisense oligonucleotides directed against stannin. Journal of Pharmacology and Experimental Therapeutics, 276, 1201-1216.

Uygur, E.E. and Arslan, M., 2010. Effects of chronic stress on cognitive functions and anxiety related behaviors in rats. Acta Physiologica Hungarica, 97, 297-306.

Wang, X. and Michaelis, E.K., 2010. Selective neuronal vulnerability to oxidative stress in the brain. Frontiers in Aging Neuroscience, 2, 1-13.

West, M.J., 2012a. Estimating object number in biological structures. Cold Spring Harbor Protocols, 2012, 1049-1066.

West, M.J., 2012b. The precision of estimates in stereological analyses. Cold Spring Harbor Protocols, 2012, 1-14.

Whittington, D.L., Woodruff, M.L., and Baisden, R.H., 1989. The timecourse of trimethyltin-induced fiber and terminal degeneration in hippocampus. Neurotoxicology and Teratology, 11, 21-33.

Yoshino, M., et al., 2004. Prooxidant activity of curcumin: copper-dependent formation of 8-hydroxy-2'-deoxyguanosine in DNA and induction of apoptotic cell death. Toxicology in Vitro, 18, 783-789.

Yuliani, S., 2015. Efek Ekstrak Kunyit (Curcuma longa, L.) Terstandar Kurkumin pada Tikus Model Demensia yang Diinduksi Trimetiltin. Thesis (PhD). UGM, Indonesia. 